\title{
Correction to: A comparative study of artificial neural networks in predicting blast-induced air-blast overpressure at Deo Nai open-pit coal mine, Vietnam
}

\author{
Hoang Nguyen ${ }^{1}$ (D) Xuan-Nam Bui ${ }^{1} \cdot$ Hoang-Bac Bui ${ }^{2} \cdot$ Ngoc-Luan Mai ${ }^{3}$
}

Published online: 16 February 2021

(C) Springer-Verlag London Ltd., part of Springer Nature 2021

Correction to: Neural Computing and Applications (2020) 32:3939-3955

https://doi.org/10.1007/s00521-018-3717-5

The corrected version of Fig. 1 is given below.
Publisher's Note Springer Nature remains neutral with regard to jurisdictional claims in published maps and institutional affiliations.

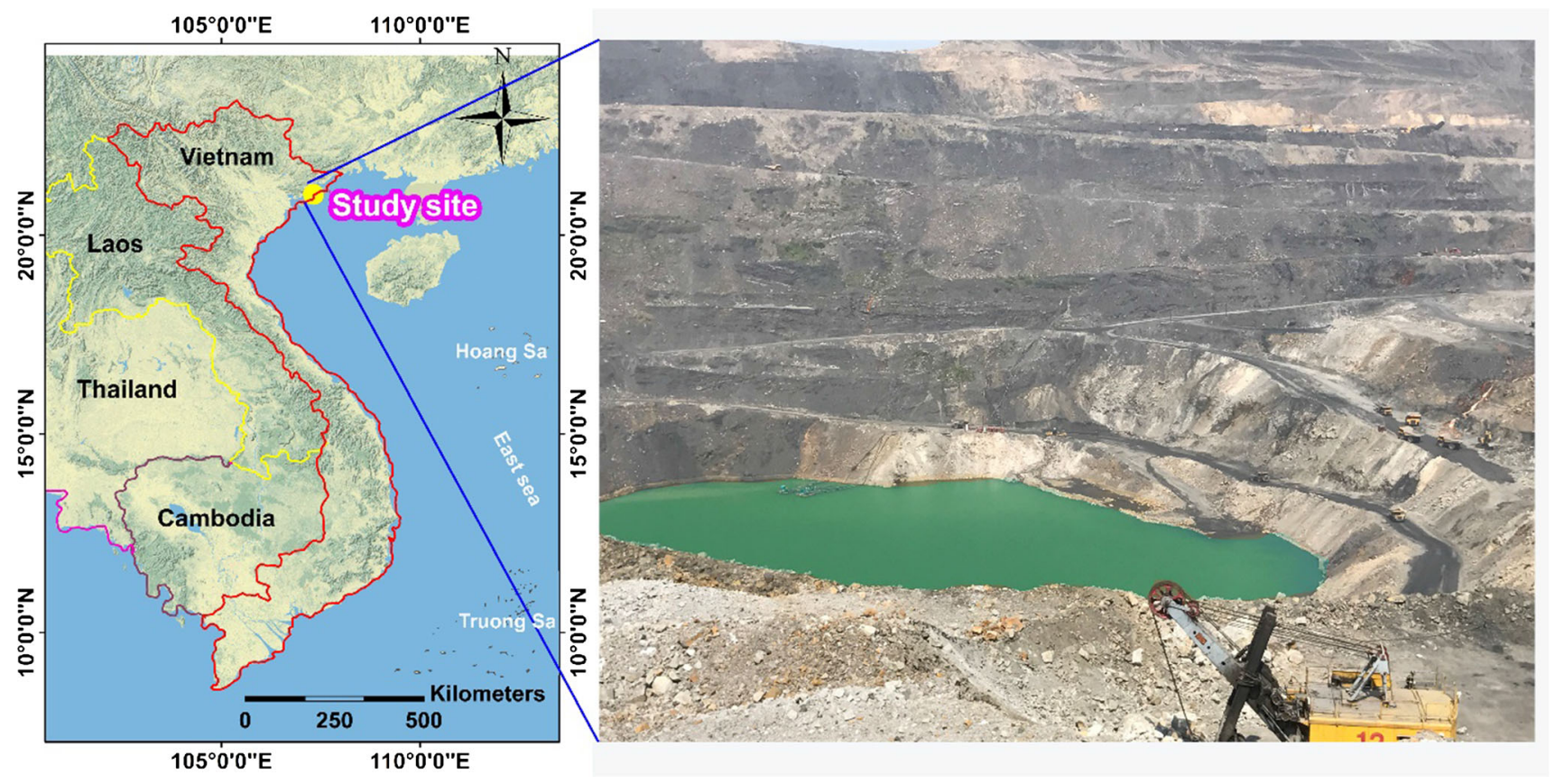

Fig. 1 Location and a view of Deo Nai open-pit coal mine in Quang Ninh Province, Vietnam

The original article can be found online at https:// doi.org/10.1007/s00521-018-3717-5.

\section{Hoang Nguyen \\ nguyenhoang@humg.edu.vn}

1 Department of Surface Mining, Mining Faculty, Hanoi University of Mining and Geology, Hanoi, Vietnam

2 Faculty of Geosciences and Geoengineering, Hanoi University of Mining and Geology, Hanoi, Vietnam

3 Visagio Australia, 6/189 St Georges Terrace, Perth, Australia 